\title{
The effect of temperature on tacticity for bulk thermal polymerization of styrene
}

\author{
Farshid Ziaee, * Mehdi Nekoomanesh, Hamid Salehi Mobarakeh, Hassan Arabi \\ Iran Polymer and Petrochemical Institute, P. O. Box 14965/115, Tehran, Iran. tel: \\ +982144580000; fax: +982144580023; e-Mail: F.Ziaee@ippi.ac.ir
}

(Received: 22 September, 2007; published: 13 March, 2008)

\begin{abstract}
Three types of polystyrenes were prepared at different temperatures of 50,150 and $250{ }^{\circ} \mathrm{C}$ by bulk thermal polymerization of styrene below 20 percent of conversion. The assignment of all stereosequences at pentad level of quaternary aromatic carbon and hexad level of methylene carbon of the polystyrenes were done using ${ }^{13} \mathrm{C}$ Liquid NMR in deuterated chloroform at similar conditions. Bernoullian and first-order Markov statistics were calculated and the results were compared with experimental NMR results. It is shown that first-order Markov statistics fit slightly better than Bernoullian statistics for the assigned carbons. The results indicated that by increasing polymerization temperature the probability of meso addition $\left(P_{m}\right)$ in polystyrene chains was enhanced. $P_{m}$ was calculated for polystyrenes prepared at 50,150 and $250{ }^{\circ} \mathrm{C}$ and corresponding values were $0.378,0.398$ and 0.402 respectively. It was shown that by increasing temperature the polymerization is directed toward the Bernoullian propagation. By increasing the NMR acquisition temperature from 20 to $65^{\circ} \mathrm{C}$ higher resolution especially in quaternary aromatic carbon was achieved and the related peak was splitted to 16 peaks corresponding to a heptad level compared to 10 peaks in $20^{\circ} \mathrm{C}$.

Key words: Microstructure, Polystyrene, NMR, Tacticity, Thermal Polymerization
\end{abstract}

\section{Introduction}

Some industrial processes of polystyrene and high impact polystyrene production are based on thermal radical polymerization. In these processes, polymerization starts at low temperature and with increasing the conversion, temperature increases as well. As a result polystyrenes with different stereosequences may be produced during the polymerization. Mechanism of thermal polymerization of styrene has been studied extensively and reported in the literature [1-3]. Stereosequences of polystyrene chains produced via thermal polymerization is assumed to be mainly atactic. Knowledge of polymer chain architecture is important to obtain information concerning relation between structure and properties [4].

One of the best analytical methods for tacticity determination of polystyrene is ${ }^{13} \mathrm{C}$ nuclear magnetic resonance analysis [5-17]. With ${ }^{13} \mathrm{CNMR}$ qualitative and quantitative analysis of tacticity can be performed [18-21]. Temperature variation could have significant effect on tacticity of polystyrene chains which are produced via different mechanisms of polymerization. Effect of temperature on changing tacticity in ionic or coordination polymerization is more pronounced than that of radical polymerization of styrene [6]. With decreasing temperature in radical polymerization, the energy difference between syndiotactic and isotactic placements exerts a progressive increasing influence on the stereospecificity of the polymerization, while at high temperature, its effect is progressively diminished [4, 22]. Since radical polymerizations are generally carried out at moderately high temperatures, most of 
the resulting polymers are highly atactic. This does not mean that there is a complete absence of syndiotacticity. There is a considerable difference in the extent of syndiotacticity from one polymer to another. For example, methylmethacrylate has a much greater tendency towards syndiotactic placement than vinyl chloride [22]. Some scientists have studied stereosequences of quaternary aromatic carbon by ${ }^{13} \mathrm{CNMR}$ [5-10] and methylene carbon [9-12] of polystyrene. By ${ }^{13}$ CNMR spectroscopy, however some others have studied and determined the probability of meso sequences. Polymer chain length must be long enough in order to determine higher sequences and ${ }^{1} \mathrm{H}$ NMR has the capability to evaluate this parameter through end group measurement [23-25]. 2DNMR was employed to evaluate polystyrene tacticity using methine carbon analysis [26].

In this work, analysis of hexad sequences of methylene and pentad sequences of quaternary aromatic carbons of polystyrene was performed using ${ }^{13} \mathrm{CNMR}$ spectroscopy in different acquisition temperatures in order to obtain Bernoullian and $1^{\text {st }}$-order Markovian probability and to compare observed and calculated data of PS which is synthesized at a broad range of polymerization temperature up to $200{ }^{\circ} \mathrm{C}$. Finally the effect of temperature on tacticity of polystyrene obtained by thermal polymerization is discussed.

\section{Results and discussion}

\section{${ }^{13}$ CNMR of quaternary aromatic carbon}

The quaternary aromatic carbon derived from the aromatic ring is a symmetric carbon and is sensitive to the monomer insertion along the macromolecular chains and resonance of this carbon shows different chemical shifts due to the microstructure. Figure 1 shows the ${ }^{13} \mathrm{C}$ solution NMR spectrum in chloroform-d for quaternary aromatic carbon ring of PS-50. Table 1 shows chemical shift assignment of the pentad sequences for this sample. These assignments are adapted from the work of Pedroza and Tavares [27]. However assignment for this section is rather complicated due to the overlapping of peaks.

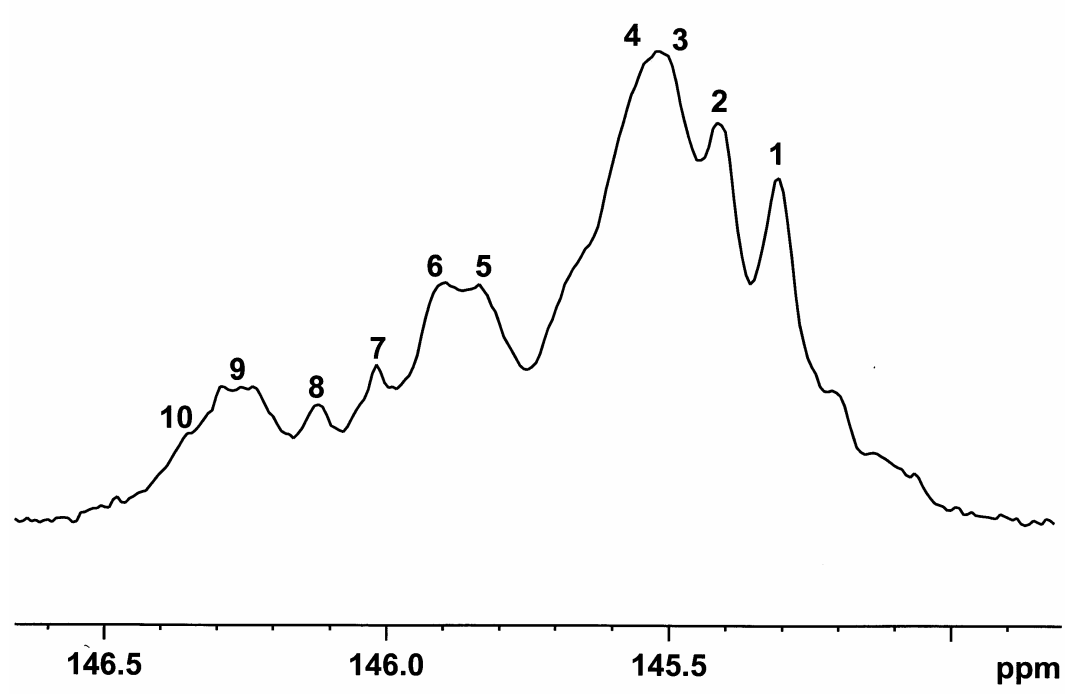

Fig. 1. Quaternary aromatic ${ }^{13} \mathrm{CNMR}$ spectrum of PS-50 in chloroform-d at $20^{\circ} \mathrm{C}$.

Physical treatments of polystyrene, temperature, molecular weight of polystyrene and type of deuterated solvent have effect on the resolution of peaks and assignment of 
the sequences [27]. Right section in quaternary aromatic carbon of polystyrene is rich in racemic sequences while the left one is rich in meso sequences.

Tab. 1. Quaternary aromatic carbon chemical shift assignment of pentad sequences for PS-50.

\begin{tabular}{rcc}
$\begin{array}{c}\text { Peak } \\
\text { No. }\end{array}$ & $\begin{array}{c}\text { Pentad } \\
\text { microstructure }\end{array}$ & $\begin{array}{c}\text { Assignment } \\
\text { (ppm) }\end{array}$ \\
\hline 1 & rrrr & 145.305 \\
2 & mrrr & 145.415 \\
3 & mrrm & 145.524 \\
4 & rmrr & 145.550 \\
5 & rmrm & 145.836 \\
6 & $\mathrm{mmrr}$ & 145.902 \\
7 & $\mathrm{mmrm}$ & 146.018 \\
8 & $\mathrm{rmmr}$ & 146.120 \\
9 & $\mathrm{mmmr}$ & 146.287 \\
10 & $\mathrm{mmmm}$ & 146.301 \\
\hline
\end{tabular}

Figure 2 compares the NMR spectra of the quaternary aromatic carbon of PS-50 and PS-250. Upfield region of PS-50 is richer in racemic sequences compared with that of PS-250. However downfield in PS-250 is richer in meso sequences than that of PS50. Normalized data for the three samples are presented in Table 2.

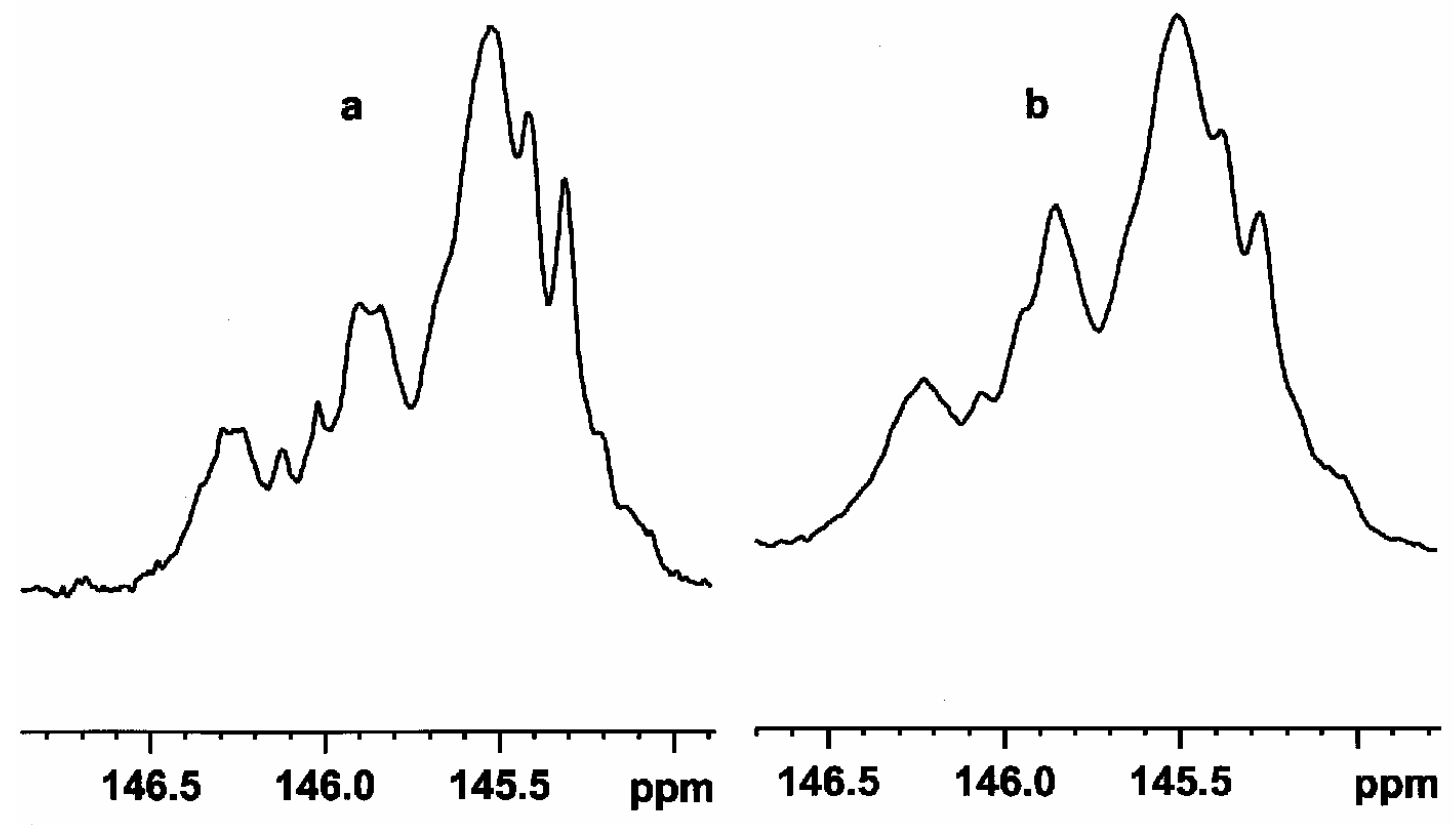

Fig. 2. Quaternary aromatic ${ }^{13} \mathrm{CNMR}$ spectrum of $\mathrm{PS}$ in chloroform-d at $20^{\circ} \mathrm{C}$, a) PS50 b) PS-250.

$P_{m}$ is defined as the probability of meso addition and is given by equation 1 .

$P_{m}=m m+1 / 2 m r$

$P_{r}=1-P_{m}=r r+1 / 2 m r$ 
There are relations between pentad, triad and dyad (equations 3-5) which enable one to calculate probability of meso sequences from higher sequences.

$\mathrm{mm}=\mathrm{mmmm}+\mathrm{mmmr}+\mathrm{rmmr}$

$\mathrm{mr}=\mathrm{mmrm}+\mathrm{mmrr}+\mathrm{rmrm}+\mathrm{rmrr}$

$\mathrm{rr}=\mathrm{mrrm}+\mathrm{mrrr}+\mathrm{rrrr}$

$P_{m}$ for three samples of polystyrene was calculated using equations 1-5 and the results are shown in Table 2. For ideal random conditions $P_{m}$ is equal to 0.5 . The results in Table 2 indicate that synthesized polystyrenes have some deviation from ideal case and for all samples the extent of racemic addition is always higher than the meso addition. Similar results have been reported earlier [5, 12]. This could be related to the bulky nature of benzene ring in styrene monomer. The other interesting point is that in the broad range of the polymerization temperature, $\mathrm{P}_{\mathrm{m}}$ value increases slightly from 0.378 at $50{ }^{\circ} \mathrm{C}$ to 0.402 at $250{ }^{\circ} \mathrm{C}$. It can be said that increasing temperature in the above range has a moderate effect on the stereoselectivity in styrene polymerization and increases random distribution of sequences. $P_{m}$ values for radical polymerization of styrene have been reported to be between 0.28 and 0.57. The $P_{m}$ values of this work are situated among the results shown in Table 3.

Tab. 2. Normalized pentad sequences of quaternary aromatic carbon, calculated Bernoullian and $1^{\text {st }}$-order Markov statistics for three PS samples.

\begin{tabular}{cccccccccc}
\hline \multirow{2}{*}{$\begin{array}{c}\text { Pentad } \\
\text { microstructure }\end{array}$} & \multicolumn{3}{c}{ PS-50 $\left(\mathrm{P}_{\mathrm{m}}=0.378\right)$} & \multicolumn{3}{c}{ PS-150 } & $\left(\mathrm{P}_{\mathrm{m}}=0.398\right)$ & \multicolumn{3}{c}{$\mathrm{PS}-250\left(\mathrm{P}_{\mathrm{m}}=0.402\right)$} \\
\cline { 2 - 10 } & Obs. & Cal. $^{\mathrm{a}}$ & Cal. $^{\mathrm{b}}$ & Obs. & Cal. $^{\mathrm{a}}$ & Cal. $^{\mathrm{b}}$ & Obs. & Cal. $^{\mathrm{a}}$ & Cal. $^{\mathrm{b}}$ \\
\hline $\mathrm{rrrr}$ & 0.1231 & 0.1497 & 0.1345 & 0.1140 & 0.1313 & 0.1211 & 0.1083 & 0.1279 & 0.1182 \\
$\mathrm{mrrr}$ & 0.1272 & 0.1819 & 0.1787 & 0.1251 & 0.1737 & 0.1713 & 0.1281 & 0.1719 & 0.1695 \\
$\mathrm{mrrm}$ & 0.1224 & 0.0553 & 0.0594 & 0.1139 & 0.0574 & 0.0606 & 0.1120 & 0.0578 & 0.0608 \\
$\mathrm{rmrr}$ & 0.2698 & 0.1819 & 0.1955 & 0.2654 & 0.1737 & 0.1834 & 0.2643 & 0.1719 & 0.1809 \\
$\mathrm{rmrm}$ & 0.0887 & 0.1106 & 0.1302 & & 0.1148 & 0.1296 & & 0.1156 & 0.1297 \\
$\mathrm{mmrr}$ & 0.0903 & 0.1106 & 0.1025 & $0.1770^{\mathrm{c}}$ & 0.1148 & 0.1089 & $0.1763^{\mathrm{c}}$ & 0.1156 & 0.1101 \\
$\mathrm{mmrm}$ & 0.0477 & 0.0672 & 0.0683 & 0.0566 & 0.0759 & 0.0770 & 0.0591 & 0.0777 & 0.0789 \\
$\mathrm{rmmr}$ & 0.0355 & 0.0553 & 0.0562 & 0.0418 & 0.0574 & 0.0582 & 0.0440 & 0.0578 & 0.0587 \\
$\mathrm{mmmr}$ & & 0.0672 & 0.0591 & & 0.0759 & 0.0692 & & 0.0777 & 0.0714 \\
$\mathrm{mmmm}$ & $0.0953^{\mathrm{c}}$ & 0.0203 & 0.0155 & $0.1062^{\mathrm{c}}$ & 0.0251 & 0.0205 & $0.1079^{c}$ & 0.0261 & 0.0217
\end{tabular}

a) Bernoullian statistic equation [19]

b) $1^{\text {st }}$-order Markov statistic equation $[19,20]$

c) two peaks overlap

Kawamura et.al. [10] divided the quaternary aromatic carbon peaks of the NMR spectra into three distinct regions and they determined the exact chemical shift for isotactic rich-meso and syndiotactic rich-racemic triads. According to their calculations, distribution of $m$ and $r$ sequences showed a reasonable agreement with Bernoullian statistics. However Inoue et.al. [5] could not find an acceptable agreement between experimental and calculated Bernoullian probabilities for pentad sequences of atactic $P S$. 
Tab. 3. Values of $P_{m}$ for radical polymerization with relevant references.

\begin{tabular}{llr}
\hline Researchers & $\mathrm{P}_{\mathrm{m}}$ & Ref. \\
\hline Inoue & 0.31 & 5 \\
Matsuzaki & 0.29 & 15 \\
Randall & 0.57 & 12 \\
Shepherd & 0.45 & 17 \\
Suparno & 0.28 & 9 \\
Sato & 0.46 & 7 \\
Kawamura & 0.46 & 10 \\
Cheng & 0.48 & 26
\end{tabular}

In order to verify agreement between experimental data and theoretical calculations Bernoullian and $1^{\text {st }}$-order Markov equations were used and the results are presented in Table 2. In $1^{\text {st }}$-order Markov polymerization the new monomer is added to the previous sequence which governs its configuration. $1^{\text {st }}$-order Markov probability is given by equations 6 and 7 .

$P_{m / r}=1-P_{m / m}=m r /(2 m m+m r)$

$P_{r / m}=1-P_{r / r}=r m /(2 r r+r m)$

$\mathrm{P}_{\mathrm{m} / \mathrm{r}}$ indicates that meso diad influences the next diad situation as a racemic diad and for example Bernoullian and $1^{\text {st }}$-order Markov statistics for mrrmm are calculated $2 \mathrm{P}_{\mathrm{m}}{ }^{3} \mathrm{P}_{\mathrm{r}}^{2}$ and $2 \mathrm{P}_{\mathrm{m}} \mathrm{P}_{\mathrm{m} / \mathrm{r}} \mathrm{P}_{\mathrm{r} / \mathrm{r}} \mathrm{P}_{\mathrm{r} / \mathrm{m}} \mathrm{P}_{\mathrm{m} / \mathrm{m}}$ respectively $[4,19,20]$.

Our results show a good agreement between observed and calculated probability for triad assignments. However, for pentad assignments there are some deviation between observed and calculated data. Some deviations in pentad analysis might be related to the imperfect assignment of the peaks.

\section{${ }^{13}$ CNMR of methylene carbon}

Some researchers have investigated the methylene carbon region of NMR spectrum of PS [9-12]. Qualitative and quantitative analysis of the methylene regions of NMR spectrum of PS solubilized in chloroform-d have shown more complexity than its solution in chlorobenzene derivatives. Randall [11, 12] and Kawamura [10] have assigned hexad splitting for methylene carbon of PS. It seems there are contradictory reports on the assignment of meso and racemic sequences in these regions. Randall contributed the assignment of rich-meso and rich-racemic peaks to the downfield and upfield regions respectively. However, Kawamura [10] and Inoue [5] concluded contrary results based on NMR spectra of isotactic and syndiotactic PS.

Figure 3 shows the hexad sequences of methylene region of ${ }^{13} \mathrm{CNMR}$ spectrum of PS-250 in chloroform- d. According to the statistics one expects to observe 20 peaks for hexad analysis of methylene carbon. However, due to some overlapping the number of peaks in Figure 3 is less than 20. The assignments of peaks observed in Figure 3 were done based on Kawamura's assignment on the hexad sequences of polystyrene methylene carbon. Table 4 contains observed and calculated Bernoullian and $1^{\text {st }}$-order Markovian statistics for the hexad of the three PS samples. In order to compare Bernoullian and $1^{\text {st }}$-order Markovian models the sum of squared difference between observed and calculated data were obtained for both quaternary carbon of 
benzene ring and methylene carbon of three PS samples and the results are summarized in Table 5.

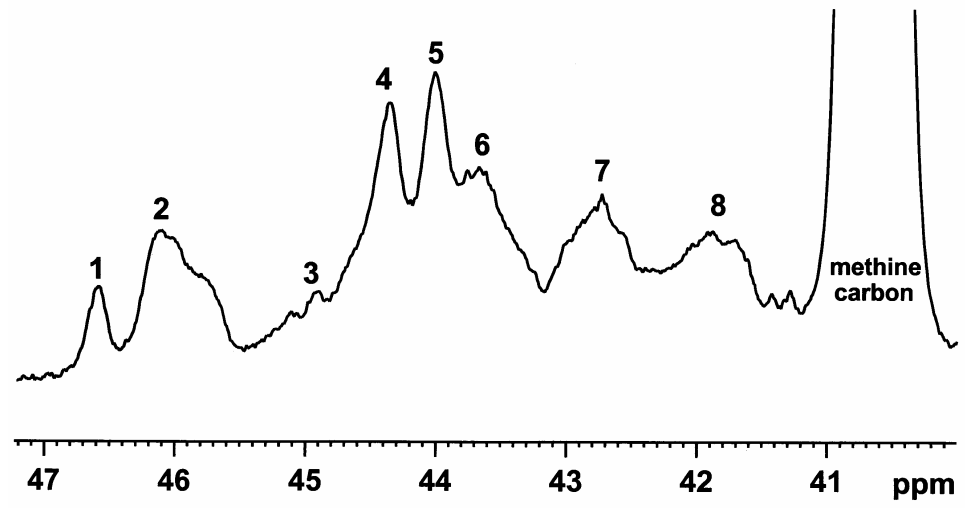

Fig. 3. Methylene ${ }^{13} \mathrm{CNMR}$ spectrum of PS-250 in chloroform-d at $20{ }^{\circ} \mathrm{C}$.

Tab. 4. Normalized hexad sequences of methylene carbon, calculated Bernoullian and $1^{\text {st }}$-order Markov statistics for three PS samples.

\begin{tabular}{|c|c|c|c|c|c|c|c|c|c|c|}
\hline \multirow{2}{*}{$\begin{array}{l}\text { Peak } \\
\text { No. }\end{array}$} & \multirow[t]{2}{*}{ Hexad Microstructure } & \multicolumn{3}{|c|}{ PS-50 } & \multicolumn{3}{|c|}{ PS-150 } & \multicolumn{3}{|c|}{ PS-250 } \\
\hline & & Obs. & Cal. $^{a}$ & Cal. $^{b}$ & Obs. & Cal. $^{a}$ & Cal. $^{b}$ & Obs. & Cal. $^{a}$ & Cal. $^{b}$ \\
\hline 1 & mrmrm & 0.0324 & 0.0209 & 0.0259 & 0.0308 & 0.0228 & 0.0269 & 0.0291 & 0.0232 & 0.0271 \\
\hline 2 & mrmrr+mrrrm+rrmrr & 0.1442 & 0.1598 & 0.1724 & 0.1341 & 0.1559 & 0.1652 & 0.1325 & 0.1551 & 0.1637 \\
\hline 3 & mrrrr & 0.0785 & 0.1132 & 0.1073 & 0.0692 & 0.1046 & 0.1002 & 0.0684 & 0.1028 & 0.0987 \\
\hline 4 & $\mathrm{mmmrm}+\mathrm{rmmrm}+\mathrm{rrrrr}$ & 0.1431 & 0.1603 & 0.1492 & 0.1505 & 0.1550 & 0.1477 & 0.1493 & 0.1542 & 0.1477 \\
\hline 5 & mmmrr+rmmrr & 0.1205 & 0.1106 & 0.1029 & 0.1202 & 0.1148 & 0.1089 & 0.1295 & 0.1156 & 0.1100 \\
\hline 6 & rmrrr+mmrrr+rmmmr & 0.1461 & 0.2029 & 0.1983 & 0.1605 & 0.1965 & 0.1930 & 0.1615 & 0.1951 & 0.1917 \\
\hline 7 & $\mathrm{mmrrm}+\mathrm{rmrrm}+\mathrm{mmmmr}+\mathrm{mmmmm}$ & 0.1790 & 0.1434 & 0.1450 & 0.1750 & 0.1551 & 0.1544 & 0.1760 & 0.1573 & 0.1567 \\
\hline 8 & $\mathrm{mmrmm}+\mathrm{mmrmr}+\mathrm{rmrmr}$ & 0.1562 & 0.0889 & 0.0992 & 0.1597 & 0.0953 & 0.1033 & 0.1538 & 0.0967 & 0.1043 \\
\hline
\end{tabular}

a) Bernoullian statistic equation [19]

b) $1^{\text {st }}$-order Markov statistic equation $[19,20]$

Table 5 shows that $\left(\sum<d>^{2}\right)$ values are reduced by increasing the polymerization temperature for both carbons. This is in accordance with the expectation of decreasing tacticity by increasing the polymerization temperature. Based on the results of Table $5,1^{\text {st }}$-order Markovian model fits slightly better with the experimental results in all temperature ranges. However, the discrepancy between experimental data and two statistics models in each temperature for both carbon types decrease with increasing polymerization temperature. Consequently, stereosequence tendency in higher temperatures approach Bernoullian statistics.

Tab. 5. Sum of squared difference between observed and calculated data $\left(\sum<d>^{2}\right)$ for quaternary and methylene carbons of the polystyrenes.

\begin{tabular}{lrrr}
\hline \multicolumn{1}{c}{$\sum\langle\mathrm{d}\rangle^{2}$} & PS-50 & PS-150 & PS-250 \\
\hline $\begin{array}{l}\text { (Bernoullian) } \\
\text { quaternary } \\
\text { methylene }\end{array}$ & $1.85 \mathrm{E}-2$ & $1.76 \mathrm{E}-2$ & $1.73 \mathrm{E}-2$ \\
& $1.10 \mathrm{E}-2$ & $7.68 \mathrm{E}-3$ & $6.68 \mathrm{E}-3$ \\
$\begin{array}{l}\text { (1)-order Markov) } \\
\text { quaternary } \\
\text { methylene }\end{array}$ & & & \\
\hline
\end{tabular}




\section{Effect of temperature in NMR analysis of polystyrene}

It is observed that by increasing the NMR acquisition temperature, resolution improves and the number of peaks increases in each region of absorption. Figure 4 shows the NMR spectra of polystyrene at different temperatures of $20,35,50$ and 65 ${ }^{\circ} \mathrm{C}$.

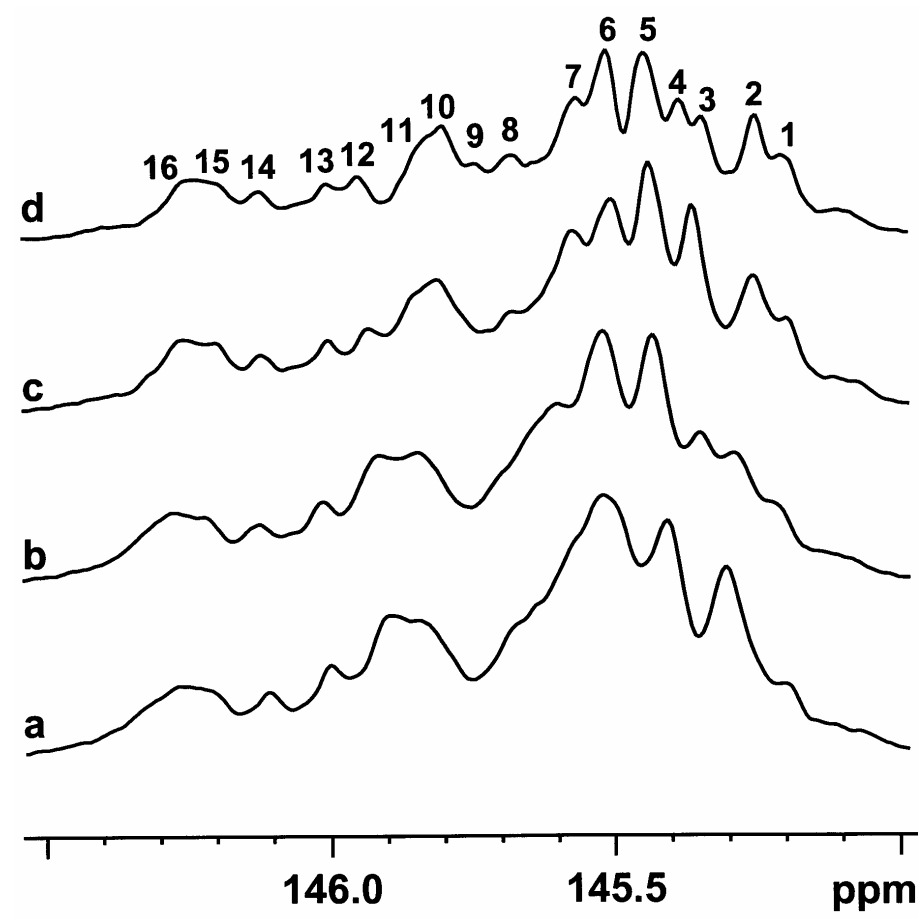

Fig. 4. Quaternary aromatic ${ }^{13} \mathrm{CNMR}$ spectrum of PS-50 in chloroform-d analysed at a) 20 , b) 35 , c) 50 and d) $65^{\circ} \mathrm{C}$

Tab. 6. Normalized heptad sequences of quaternary aromatic carbon for PS-50 analysed at $65^{\circ} \mathrm{C}$.

\begin{tabular}{|c|c|c|c|c|c|c|c|}
\hline \multirow{2}{*}{$\begin{array}{l}\text { Peak } \\
\text { No. }\end{array}$} & \multirow[t]{2}{*}{ Microstructure } & \multicolumn{2}{|c|}{ Intensity } & \multirow{2}{*}{$\begin{array}{l}\text { Peak } \\
\text { No. }\end{array}$} & \multirow[t]{2}{*}{ Microstructure } & \multicolumn{2}{|c|}{ Intensity } \\
\hline & & Obs. & Cal. & & & Obs. & Cal. \\
\hline 1 & rrrrrr & 0.0376 & 0.0578 & 9 & Rrmrmr & 0.0303 & 0.0428 \\
\hline 2 & mrrrrm+rrrrrm & 0.0819 & 0.0918 & 10 & $\begin{array}{l}\text { mrmrmr+rrmrmm+ } \\
\text { mrmrmm }\end{array}$ & 0.0618 & 0.0678 \\
\hline 3 & rmrrrr+rmrrrm & 0.0621 & 0.1132 & 11 & rmmrrr & 0.0474 & 0.0428 \\
\hline 4 & mmrrrm+mmrrrr & 0.0450 & 0.0688 & 12 & $\begin{array}{l}\text { rmmrrm+mmmrrr+ } \\
\text { mmrrm }\end{array}$ & 0.0436 & 0.0678 \\
\hline 5 & mrrm & 0.1292 & 0.0553 & 13 & mmrm & 0.0409 & 0.0672 \\
\hline 6 & rrmrrr & 0.1128 & 0.0704 & 14 & $\mathrm{rmmr}$ & 0.0360 & 0.0553 \\
\hline 7 & rrmrrm+mrmrrr & 0.1298 & 0.0855 & 15 & $\mathrm{rmmmr}$ & 0.0328 & 0.0260 \\
\hline 8 & mrmrrm & 0.0534 & 0.0260 & 16 & $\begin{array}{l}\mathrm{mmmmrr}+\mathrm{rmmmrm}+ \\
\mathrm{mmmmrm}+\mathrm{mmmm}\end{array}$ & 0.0554 & 0.0615 \\
\hline
\end{tabular}


As it can be seen from Figure 4 the number of peaks is increased from 10 to 16 . Furthermore, it can be said that some heptad sequences, are presented in the NMR spectrum at $65{ }^{\circ} \mathrm{C}$ which were not seen at lower temperatures. These new peaks are assigned upon sequence order and the proposed assignments are presented in Table 6. Based on the results of $P_{m}$ and calculated heptad sequence distribution, fairly good agreement was observed between the theoretical and experimental results. It is worth to be noted that higher splitting will increase the standard deviation.

Figure 5 shows the spectra of methylene carbon (right) and para carbon of benzene ring (left) in different temperatures from 20 to $65^{\circ} \mathrm{C}$. Figure 5 (right) shows that with increasing temperature, peaks No. 2 and No. 6 in methylene carbon observed in Figure 3 are splitted into two separate peaks and the total number of peaks arises from eight to ten peaks.
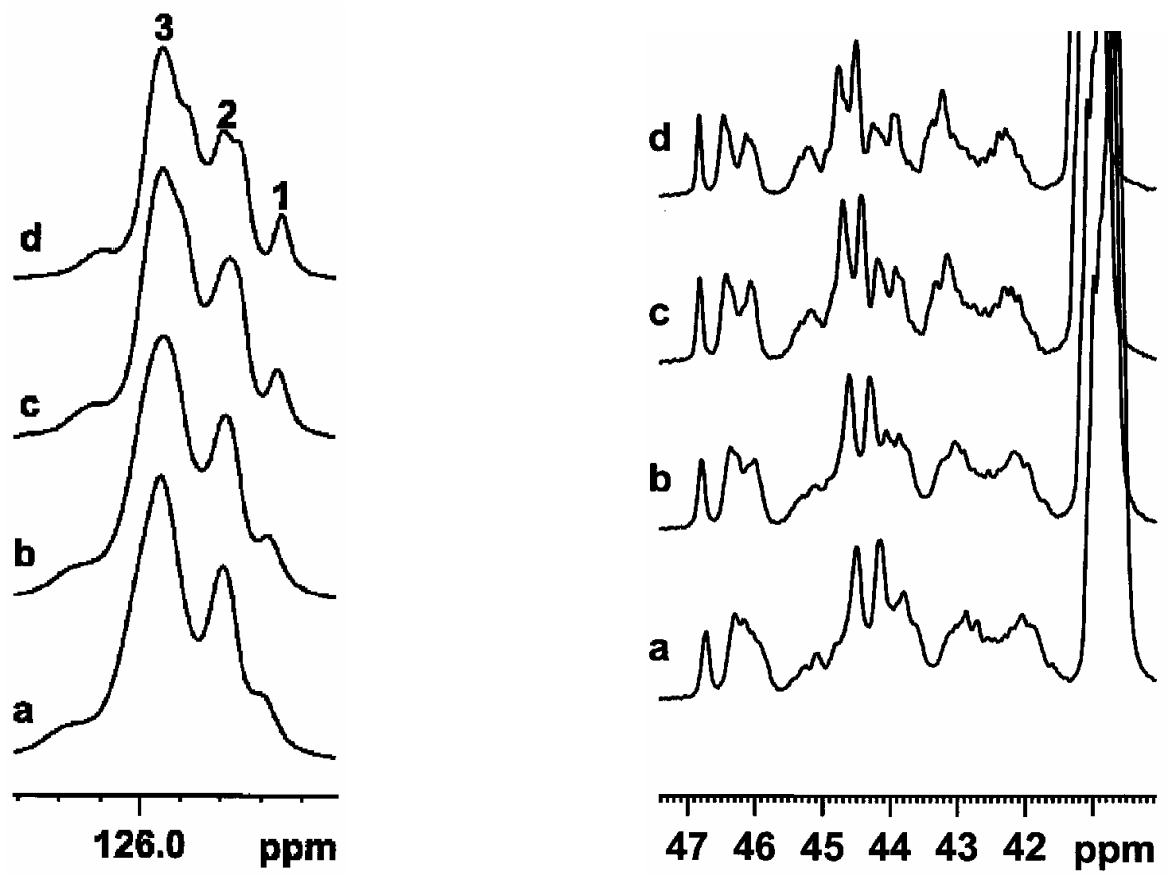

Fig. 5. Methylene (right) and Para aromatic carbon (left) ${ }^{13} \mathrm{CNMR}$ spectrum of PS-50 solution in chloroform-d at a) 20 , b) 35 , c) 50 and d) $65^{\circ} \mathrm{C}$.

It can be seen from Figure 5 (left) that by increasing temperature, higher resolution as well as higher splitting of the peaks are achieved. Same phenomenon happened for para carbon of benzene ring. This carbon splits in triad sequences; on increasing temperature pentad sequences appear in the spectrum and better resolution is obtained. In fact this peak is composed of isotactic structure in upfield and syndiotactic structure in downfield. Figure 5 (left) depicts region of para carbon of benzene ring at four different temperatures. It seems that in this region triad sequences are overlapped and experimental results do not show an acceptable match with quaternary carbon of benzene ring.

\section{Conclusions}

Thermal bulk polymerization of styrene at three different temperatures was carried out. Assignment of all stereosequences was performed on quaternary aromatic 
carbon at pentad level and methylene carbon at hexad level using ${ }^{13} \mathrm{CNMR}$ spectroscopy. Observed data were compared with Bernoullian and $1^{\text {st }}$-order Markovian statistics. The results showed that $1^{\text {st }}$-order Markovian propagation fit slightly better with the experimental results. Increasing polymerization temperature reduced the discrepancy between observed data and both calculated statistical models indicating that stereosequences approach Bernoullian statistics in higher temperatures. Acceptable compatibility for other sequences indicates that styrene monomer has higher tendency to add by racemic configuration to its growing radical at all polymerization temperatures. NMR analysis was also performed in higher temperatures and it was shown that better resolution and higher splitting up to heptad sequences for quaternary aromatic carbon was achieved and para aromatic carbon splitting in triad sequences were better resolved.

\section{Experimental}

\section{Materials}

Styrene monomer was obtained from Merck chemical Co. Inc. To remove the inhibitor it was washed three times with a $5 \%$ sodium hydroxide solution followed by three times distilled water and then dried over calcium chloride. Freshly distilled monomer under vacuum was used. Solvents (toluene (Merck) and methanol) were used as received without further purification.

\section{Polymerization}

Thermal polymerization of styrene was conducted in stainless steel ampoules sealed under vacuum at $10^{-1} \mathrm{mmHg}$. The ampoules were $15 \mathrm{~cm}$ in length with an inlet diameter of $8 \mathrm{~mm}$ and wall thickness of $2 \mathrm{~mm}$. The ampoules were degassed by several vacuum freeze-thaw cycles and polymerizations were done in oil bath. Thermal / bulk polymerization was conducted at temperatures indicated in Table 7. During the reaction, temperature was maintained constant within $\pm 0.1^{\circ} \mathrm{C}$ of the desired temperature. Termination of the polymerizations was done by quenching the ampoules in liquid nitrogen. The reaction mixtures were dissolved in toluene and polymers were precipitated out in a 25 -fold excess of chilled methanol. The filtrate was washed several times with fresh methanol. It was then dried at $40{ }^{\circ} \mathrm{C}$ under vacuum to constant weight. To insure the repeatability each experiment was repeated at least once.

Tab. 7. Synthesis conditions of polymerization.

\begin{tabular}{lrrr}
\hline Sample & $\begin{array}{r}\text { Temperature } \\
\left({ }^{\circ} \mathrm{C}\right)\end{array}$ & $\begin{array}{r}\text { Time } \\
(\min )\end{array}$ & $\begin{array}{c}\text { Conversion } \\
(\%)\end{array}$ \\
\hline PS-50 & 50 & 2880 & 2 \\
PS-150 & 150 & 30 & 15 \\
PS-250 & 250 & 1 & 20 \\
\hline
\end{tabular}

\section{Characterization}

Solution NMR spectra was obtained on a Bruker Avance $400 \mathrm{MHz}$, operating at 100.6 MHz for ${ }^{13} \mathrm{C}$. Sample concentration for ${ }^{13} \mathrm{C}$ analysis was about $50 \mathrm{mg}$ of PS in $1 \mathrm{ml}$ of chloroform-d using a $5 \mathrm{~mm}$ NMR tube with screw cap under pressure at 20, 35,50 and $65{ }^{\circ} \mathrm{C} .{ }^{13} \mathrm{CNMR}$ spectra were acquired using $32 \mathrm{k}$ data points, spectral width 220 ppm, acquisition time $1.59 \mathrm{~s}$, relaxation delay 2 "Ss, pulse width $90^{\circ}$ and 
40000 scans and the NOE were suppressed by gating the decoupler sequence. NMR spectra were treated with XWIN-NMR software version 3.5.

\section{Acknowledgements}

The author wish to acknowledge NPC - rt for financial support of this work.

\section{References}

[1] Husain, A.; Hamielec, A. E. J. Appl. Polym. Sci. 1978, 22, 1207.

[2] Hui, A. W.; Hamielec, A. E. J. Appl. Polym. Sci. 1972, 16, 749.

[3] Brown, W. G. Die Makromol. Chem. 1969, 128, 130.

[4] Moad, G.; Solomon, D. H. The Chemistry of Free Radical Polymerization, Elsevier Science Ltd. 2006.

[5] Inoue, Y.; Nishioka, A.; Chujo, R. Die Makromol. Chem. 1972, $156,207$.

[6] Kawamura, T.; Uryu, T.; Matsuzaki, K. Makromol. Chem. 1979, 180, 2001.

[7] Sato, H.; Tanaka, Y.; Hatada, K. J. Polym. Sci., Polym. Phys. Edn. 1983, 21, 1667.

[8] Jasse, B.; Laupretre, F.; Monnerie, L. Makromol. Chem. 1977, 178, 1987.

[9] Suparno, S.; Lacoste, J.; Rayal, S.; Regnier, J.F.; Schue, F.; Sempere, R.; Sledz, J. Polymer J. 1980, 12, 861.

[10] Kawamura, T.; Toshima, N.; Matsuzaki, K. Macromol. Rapid Commun. 1994, 15, 479.

[11] Randall, J. C. J. Polym. Sci., Polym. Phys. Edn. 1976, 14, 2083.

[12] Randall, J. C. J. Polym. Sci., Polym. Phys. Edn. 1975, 13, 889.

[13] Kawamura, T.; Uryu, T.; Matsuzaki, K. Makromol. Chem., Rapid Commun. 1982, 3,661 .

[14] Sato, H.; Tanaka, Y.; Hatada, K. NMR and Macromolecules, ACS Symposium Series, American Chemical Society 1984.

[15] Matsuzaki, K.; Uryu, T.; Osada, K.; Kawamura, T. Macromolecules 1972, 5, 816.

[16] Mani, R.; Burns, C. M. Macromolecules 1991, 24, 5476.

[17] Shepherd, L.; Chen, T.K.; Harwood, H.J. Polym. Bull. 1979, 1, 445.

[18] Randall, J. C. Polymer Sequence Determination Carbon $-{ }^{13}$ CNMR Method, Academic Press 1977.

[19] Bovey, F. Nuclear Magnetic Resonance Spectroscopy, Bell Telephone Laboratories 1988.

[20] Tonelli, A. NMR Spectroscopy and Polymer Microstructure, VCH 1989.

[21] Pham, Q.; Petiaud, R.; Watson, H.; Darricades, M. F. L. Proton and Carbon NMR Spectra of Polymers, Penton Press, London 1991.

[22] Odian, G. Principles of Polymerization, John Wiley and Sons 1981.

[23] Yoshikawa, C.; Goto, A., Fukuda, T. e-Polymers 2002, no. 013.

[24] Durmaz, Y. Y.; Cianga, I.; Yagci, Y. e-Polymers 2006, no. 050.

[25] Bevington, J. C.; Hukerby, T. N. Eur. Polym. J. 2006, 42, 1433.

[26] Cheng, H. N.; Lee, G.H. Inter. J. Polym. Anal. Charac. 1996, 2, 439.

[27] Pedroza, O. J. O.; Tavares, M. I. B. Polym. Test. 2005, 24, 604. 